Family Medicine and Community Health

\section{Physicians' views on the usefulness of practical tools for assessing the driving ability of older drivers: a cross- sectional study}

To cite: Sebo P. Physicians' views on the usefulness of practical tools for assessing the driving ability of older drivers: a cross-sectional study. Fam Med Com Health 2020;8:e000332. doi:10.1136/fmch-2020-000332

\section{Check for updates}

(c) Author(s) (or their employer(s)) 2020. Re-use permitted under CC BY-NC. No commercial re-use. See rights and permissions. Published by BMJ.

Primary Care Unit, Faculty of Medicine, University of Geneva Geneva, Switzerland

Correspondence to

Dr Paul Sebo;

paulsebo@hotmail.com

\section{ABSTRACT}

Objective We aimed to explore Swiss physicians' views on the usefulness of a self-administered questionnaire completed by older drivers before the consultation and a reference guide summarising current Swiss guidelines on the fitness-to-drive assessment of older drivers. We also aimed to assess the frequency with which physicians used the information sources provided by the Swiss traffic medicine website.

Design Questionnaire-based cross-sectional study. Setting The study was conducted in four cantons of Western Switzerland (Geneva, Vaud, Neuchâtel and Jura). Participants All physicians certified to carry out fitnessto-drive assessments in the canton of Geneva (medical assessors; $n=69$ ) and a random sample of 500 general practitioners practising in the cantons of Vaud, Neuchâtel and Jura were invited to participate. They were asked to report their estimated average number of fitness-to-drive assessments per week and to rate on a 5-point Likert scale the perceived usefulness of the preconsultation patient questionnaire and reference guide, and the frequency of use of the information sources provided by the traffic medicine website. We computed the proportion of physicians who found the assessment tools very/ somewhat useful and the proportion of physicians who always/often used the traffic medicine website. We compared the responses according to medical specialty (medical assessors vs general practitioners) using designbased $F$ tests and weighted logistic regressions.

Results 268 physicians (47\%) agreed to participate in the study. Their median number of assessments was 2 per week (IQR 2). Overall, the majority of physicians found the questionnaire $(75 \%)$ and reference guide $(89 \%)$ very/somewhat useful. Only $17 \%$ of the sample always/ often used the traffic medicine website. There were no statistically significant associations in multivariable analysis between the medical specialty and the perceived usefulness of the questionnaire and reference guide and the frequency of use of the traffic medicine website. Conclusion Many physicians find the preconsultation patient questionnaire and reference guide useful to guide them for assessing the driving ability of older drivers, but only a minority regularly use the information sources provided by the traffic medicine website. Future studies should explore the reasons why many physicians do not use these available sources of information.

\section{INTRODUCTION}

With increased longevity and improved health of older drivers, the number of older drivers is expected to increase over the next decades. ${ }^{12}$ Although older drivers tend to have more favourable driving habits, for example, in terms of observation of speed limits, ${ }^{13}$ a number of health issues occurring more often in the elderly, such as sensory, motor or cognitive decline, could impair their driving performance. ${ }^{45}$

National programmes for assessing older drivers' fitness to drive have been developed in several countries, ${ }^{6}$ although there is no agreement to date on the level of association between the result of these assessments and future driving ability. ${ }^{7-9}$ In Switzerland, at the time of the study, a medical examination was mandatory every 2 years for all drivers over 70 years of age. A revision of the Road Traffic Act that came into force after the end of the study (in January 2019) raised the minimum age for this medical examination to 75 . This examination is carried out by general practitioners (GPs), except in Geneva where it is undertaken by the medical assessors of the road traffic office. These assessors are all physicians and most of them are also GPs (of the 69 medical assessors 60 were GPs at the time of the study). The prerequisites for carrying out these examinations vary from canton to canton: in Geneva, medical assessors have to attend a 1 day theoretical training course, whereas in other cantons, GPs only have to identify themselves to the competent cantonal authorities.

Physicians are asked to identify medical conditions that could affect the driving ability of older drivers. At the end of the assessment, they complete a form, which is returned to the road traffic office with a general recommendation (fit to drive, fit to drive with constraints, unfit to drive or further 
Table 1 Older driver preconsultation self-administered questionnaire on health

Item
Changes in health status since the last medical examination for fitness to drive
Current or past medical conditions:

Eye problem, and/or wearing glasses or contact lenses

Sleep apnoea and/or other diseases leading to daytime sleepiness

Cardiac or vascular disease: high or low blood pressure, chest pain, heart attack, coronary bypass, coronary angiography, palpitations, irregular heartbeat, arrhythmia, pacemaker or defibrillator, thrombosis, embolism, aneurysm, and so on

Pulmonary disease: asthma, chronic bronchitis, emphysema, difficulty breathing

Diabetes and/or other metabolic disease

Problems with memory and/or concentration

Neurological disease: epilepsy or other seizure disorder, Parkinson's disease, stroke, paralysis, multiple sclerosis, lightheadedness, fainting spells or loss of consciousness, and so on

Problems with balance and/or dizziness

Deafness

Bone or joint disease: chronic pain, osteoarthritis, rheumatism, and so on

Digestive problems: liver disorder, and so on

Kidney disease: kidney failure, dialysis, and so on

Psychological problem: depression, schizophrenia, psychosis, bipolar disorder, and so on

Alcohol problem

Psychotropic drug abuse: anxiolytics, sleeping pills, and so on

Illegal drug use: cannabis, heroin, methadone, cocaine, and so on

Injury requiring surgery and/or with after-effects

Other diseases or disabilities that may interfere with safe driving

List and dates of past hospitalisations:

List and dates of past surgeries:

List of current drugs:

Driver's licence revoked for any reason: drink-driving, drug-driving, speeding, and so on

evaluation required). About $2 \%$ of older drivers are considered medically unfit to drive in Switzerland, mainly due to cognitive $(64 \%)$ and visual $(18 \%)$ impairments. ${ }^{10}$ This figure does not include older drivers who are considered unfit after reports from the police, family members or health professionals. In Switzerland, health professionals can report patients they consider unfit to drive to the road traffic office at any time (these patients then undergo a thorough medical assessment and possibly a temporary or permanent licence revocation). However, this is a voluntary procedure; physicians do not have the legal obligation to report unfit-to-drive patients to the competent authority.

To simplify their task, physicians can use the information sources provided by the traffic medicine website ( medtraffic.ch) and the publications of traffic medicine experts in local medicine journals. ${ }^{11}$ In addition, traffic medicine experts have recently developed a standardised self-administered questionnaire based on Swiss recommendations that can be completed by older drivers before the consultation and used by physicians to guide their assessment (see table 1 for the English version of the older driver preconsultation self-administered questionnaire on health). As part of the development of self-assessment instruments promoting self-regulation, the self-administered questionnaire could also be completed by older drivers at home in order to help raise awareness of their driving skills.

To our knowledge, there are no studies in Switzerland that explored physicians' views on the usefulness of these practical tools and information sources. Only a few foreign studies addressed this theme. A Canadian study found that a large number of physicians were not aware (24\%) and, among those who were aware, did not use (31\%) the reference book published by the Canadian Medical Association titled Determining medical fitness to drive: a guide for physicians. ${ }^{12}$ An American study found that $69 \%$ of physicians were not aware of the American Medical Association guidelines regarding medical conditions affecting older drivers. ${ }^{13}$

In this study, we aimed to explore physicians' views on the usefulness of two practical tools to guide fitnessto-drive assessments and the use by physicians of the information sources provided by the Swiss traffic medicine website, first overall and then according to physicians' characteristics. In particular, we aimed to compare responses according to whether participants were medical assessors or GPs. Our hypothesis was that those who were 
not medical assessors, those who were younger physicians and those with fewer fitness-to-drive assessments (because these physicians are generally less experienced), and female physicians (because they are more likely to follow the recommendations than their male counterparts) ${ }^{14}$ would find these two practical tools more useful and visit the traffic medicine website more often.

\section{METHODS}

As planned by the study team, this cross-sectional study was nested within a practice review carried out in 2017, designed to describe the fitness-to-drive assessment practices of physicians in the French-speaking part of Switzerland. ${ }^{11}$ The manuscript follows the Strengthening the Reporting of Observational Studies in Epidemiology guidelines for reporting observational studies.

\section{Survey site, survey population and data collection}

We randomly selected 500 GPs practising in the cantons of Vaud, Jura and Neuchâtel (sample fraction: 500/1075; probability weight: 2.15), hereinafter referred as 'regular practice GPs'. We also selected all medical assessors of the road traffic office in Geneva ( $\mathrm{n}=69$; probability weight: 1$)$. All medical assessors and selected regular practice GPs were asked to complete a paper questionnaire with sociodemographic items (gender, age, practice location, number of half days worked per week) and questions about fitness-todrive assessments (estimated mean number of assessments per week and content of their assessments). In addition, physicians were asked to rate the perceived usefulness of a standardised questionnaire completed by older drivers before the consultation and a reference guide summarising the Swiss recommendations on the fitness-to-drive assessment of older drivers, on a 5-point Likert scale ranging from 'not useful' (0) to 'very useful' (4). Finally, they were asked to rate the frequency of use of the information sources provided by the traffic medicine website (medtraffic.ch), on a 5-point Likert scale ranging from 'never used' $(0)$ to 'always used' (4).

For the part of the questionnaire dealing with the content of fitness-to-drive assessments, physicians were asked to report the procedures they performed during the assessments (see box 1: medical fitness to drive/ driving history patient questionnaire), scoring them on a 5-point Likert scale ranging from 'never performed' (0) to 'always performed' (4). These items were selected by consensus within the research team, which included three traffic medicine specialists and three academic GPs. The questionnaire was pretested with five GPs practising in Geneva.

\section{Confidentiality and ethical approval}

All collected data remained confidential. We presumed tacit consent if the physicians sent back the questionnaire. According to Swiss law, this study did not require ethical review, because we did not collect personal healthrelated data.
Box 1 Medical fitness to drive/driving history patient questionnaire

Screening

- Screening for cognitive impairment for drivers aged $>80$ years.

- Screening for cognitive impairment for drivers aged between 70 and 80 years.

- Screening for mood disorder (depression and anxiety).

- Screening for at-risk drinking.

- Screening for use of psychotropic drugs.

- Screening for daytime sleepiness.

- Screening for use of antidiabetic drugs.

- Screening for visual acuity impairment.

- Screening for visual field impairment.

- Screening for diplopia.

- Screening for hearing impairment.

- Screening for gait and balance disorder.

Medical history

- Asking for the list of current medication.

- Asking for history of cardiovascular diseases.

- Asking for history of neurological diseases.

- Asking for history of psychiatric diseases.

Driving history

- Asking for recent changes in driving habits.

- Interviewing close relatives about medical history and/or changes in driving habits.

- Asking for history of traffic accidents.

- Asking for history of driving licence withdrawal.

\section{Statistical analyses and sample size}

We described physicians' characteristics (sociodemographic characteristics and those related to fitness-todrive assessments), using frequency tables for categorical variables, and medians and IQR for numerical data (not normally distributed). We compared these characteristics between medical assessors and regular practice GPs using design-based $F$ tests (corrected weighted Pearson $\chi^{2}$ tests) for categorical variables and Wilcoxon rank-sum tests for numerical data.

We computed the proportion of physicians who judged that these assessment tools would be very useful $(4 / 4)$ or somewhat useful $(3 / 4)$, and the proportion of physicians who always $(4 / 4)$ or often $(3 / 4)$ use these information sources, and we compared the responses between physicians' subgroups using design-based $F$ tests. For these tests, we dichotomised the number of fitness-to-drive assessments into $\leq 2$ and $>2$ per week and the number of procedures often or always performed into $<15$ and $\geq 15$. The cut-off points were set at 2 and 15, respectively, as they were the medians of the distribution. We used survey data analyses because we had to take into account the stratified random sampling.

Finally, we carried out weighted logistic regressions for all variables showing statistically significant differences between the subgroups, to assess whether the observed differences could be due to sociodemographic factors.

The required sample size was computed for the practice review. ${ }^{11}$ For the current study, we wanted a $95 \%$ CI 
Table 2 Physicians' characteristics, overall, and stratified into two groups according to whether they are medical assessors of the road traffic office or regular practice GPs $(n=268)$

\begin{tabular}{|c|c|c|c|c|}
\hline & Total $^{*}$ & $\begin{array}{l}\text { Medical } \\
\text { assessors }(n=45) \\
\end{array}$ & $\begin{array}{l}\text { Regular practice } \\
\text { GPs ( } n=223) \\
\end{array}$ & \\
\hline Characteristics & n (\%) & n (\%) & n (\%) & $\mathrm{P}$ value \\
\hline Gender $(n=266)$ & & & & 0.01 \\
\hline Male & $177(66.5)$ & $35(81.4)$ & $142(63.7)$ & \\
\hline Female & $89(33.5)$ & $8(18.6)$ & $81(36.3)$ & \\
\hline Age group (years) $(n=266)$ & & & & 0.04 \\
\hline$<45$ & $56(21.1)$ & $7(15.6)$ & $49(22.2)$ & \\
\hline $45-54$ & $65(24.4)$ & $8(17.8)$ & $57(25.8)$ & \\
\hline $55-64$ & $97(36.5)$ & $19(42.2)$ & $78(35.3)$ & \\
\hline$\geq 65$ & $48(18.0)$ & $11(24.4)$ & $37(16.7)$ & \\
\hline Location of practice $(n=263)$ & & & & $<0.001$ \\
\hline Urban & $196(74.5)$ & $44(97.8)$ & $152(69.7)$ & \\
\hline \multirow[t]{2}{*}{ Rural } & $67(25.5)$ & $1(2.2)$ & $66(30.3)$ & \\
\hline & Median (IQR) & Median (IQR) & Median (IQR) & \\
\hline Number of half days worked per week $(n=261)$ & $8(3)$ & $9(2)$ & $8(3)$ & 0.03 \\
\hline $\begin{array}{l}\text { Number of fitness-to-drive assessments per week } \\
(\mathrm{n}=264)\end{array}$ & $2(2)$ & $5(3)$ & $1(1)$ & $<0.001$ \\
\hline $\begin{array}{l}\text { Number of procedures often or always performed } \\
(n=209)\end{array}$ & $14(5)$ & $15(4)$ & 14 (5) & 0.56 \\
\hline
\end{tabular}

*Numbers do not add to 268 because of missing data.

†Design-based $F$ tests (corrected weighted Pearson $\chi^{2}$ tests) for categorical variables and Wilcoxon rank-sum tests for numerical data. GPs, general practitioners.

width of about $0.15(15 \%)$ around the estimate. Given the formula for the estimation of a proportion $\left(n=1.96^{2} \times\right.$ proportion $\times(1$-proportion $) /$ precision $\left.^{2}\right)$, the minimal sample size required for the study was 171 (proportion used in the formula $=0.5$ ). The sample size estimated for the practice review met these requirements.

Statistical significance was set at a two-sided $p$ value $\leq 0.05$. All statistical analyses were carried out with STATA V.12.0 (College Station, USA).

\section{RESULTS}

\section{Study population}

Two hundred and sixty-eight physicians (47\%) agreed to participate in the study (medical assessors: 45, regular practice GPs: 223). Table 2 presents their main characteristics. The majority of participants were male $(67 \%)$ and practising in urban areas $(75 \%)$; they were rather experienced physicians (more than half of them were older than 55 years). The median number of assessments carried out was 2 per week, $14 \%$ of physicians performing less than one assessment, $36 \%$ one assessment, $21 \%$ two assessments and 29\% more than two assessments per week. Finally, the median number of procedures physicians often or always performed was 14. Compared with regular practice GPs, those practising as medical assessors were more often male, slightly older and practising more often in urban areas. In addition, the median number of assessments per week was five times higher for medical assessors than for regular practice GPs (median: 5 vs 1 ). Our sample of physicians (medical assessors excluded) appear to be representative of all physicians practising in Switzerland in terms of age (median age: 54 years in Switzerland vs 57 years in our study), but slightly less in terms of gender distribution (men: $59 \%$ in Switzerland vs $64 \%$ in our study). ${ }^{15}$

\section{Perceived usefulness of the preconsultation patient questionnaire}

Overall, three-quarters of physicians judged that the preconsultation patient questionnaire would be very $(43 \%)$ or somewhat useful (32\%) to guide their assessments (table 3). There were no statistically significant differences between physicians' subgroups, although older physicians tended to consider the questionnaire less useful.

\section{Perceived usefulness of the reference guide}

The majority of physicians also judged that the reference guide would be very $(62 \%)$ or somewhat useful $(27 \%)$. As shown in table 3 , in univariate analysis, medical specialty and age were statistically significantly associated with the perceived usefulness of the guide, with medical assessors and older physicians finding the reference guide less useful (both $\mathrm{p}$ values 0.03 ). In multivariable analysis, these associations were not statistically significant. 


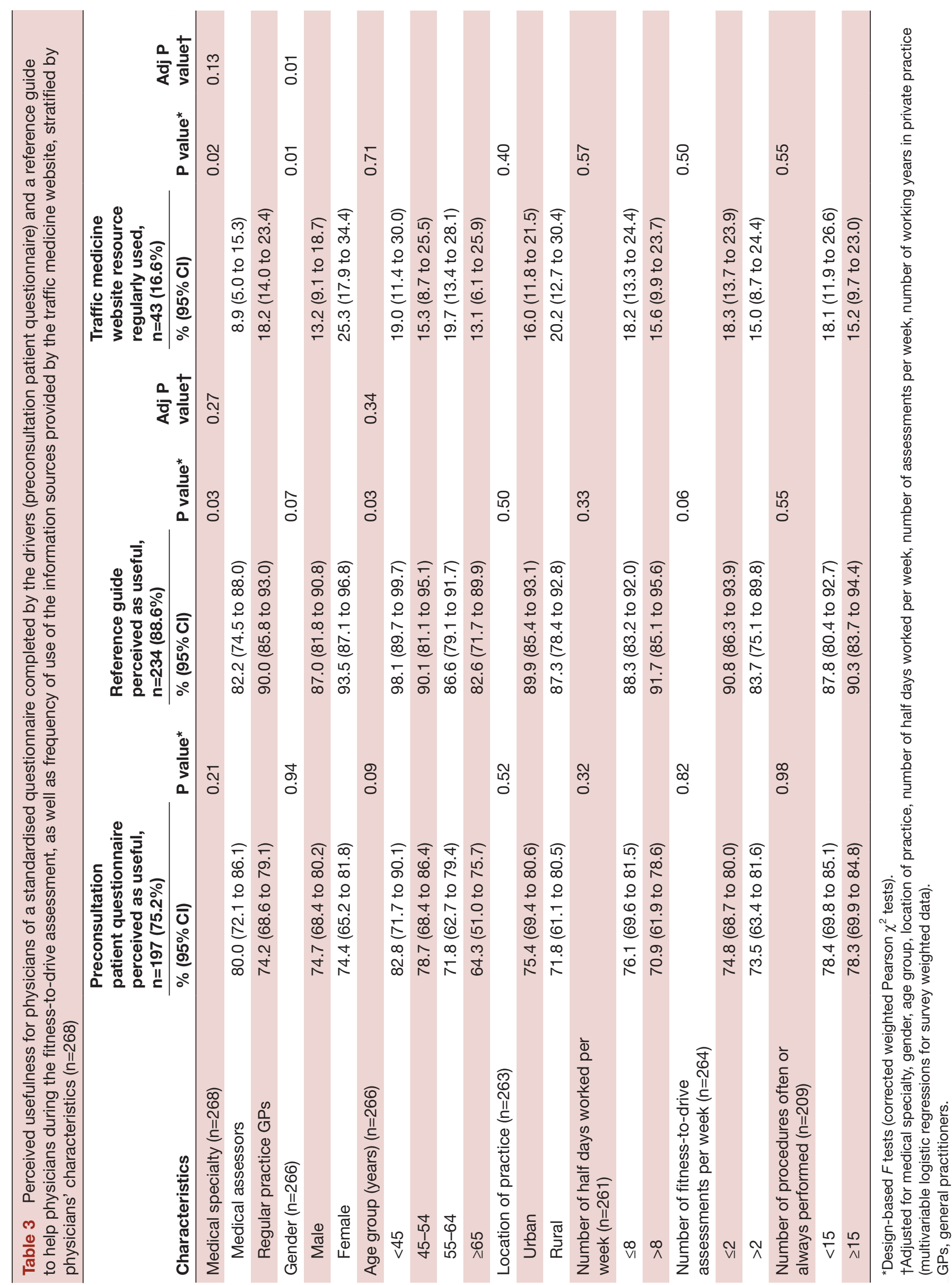


Use of the information sources provided by the traffic medicine website

Overall, only a minority of physicians $(17 \%)$ regularly used these information sources (table 3). Almost one-third of physicians $(31 \%)$ have never used them (data not shown in the table). In univariate analysis, medical specialty (regular practice GPs) and gender (female) were statistically significantly associated with regular use of the website resource. The association with gender (but not with medical specialty) was statistically significant in multivariable analysis, with female physicians being more likely to use these information sources than their male counterparts (adjusted OR 2.9 (95\% CI 1.3 to 6.1 ), $\mathrm{p}=0.01$ ).

\section{DISCUSSION}

\section{Main finding}

We found that the median number of fitness-to-drive assessments carried out by our sample of physicians was 2 per week. We also found that the majority of physicians considered that a self-administered questionnaire completed by older drivers before the consultation and a reference guide summarising the Swiss recommendations on the fitness-to-drive assessment of older drivers would be very/somewhat useful. However, less than onefifth of them always/often used the information sources provided by the traffic medicine website. Finally, there were no statistically significant associations between the medical specialty (medical assessors or GPs) and the perceived usefulness of the preconsultation patient questionnaire and reference guide and the frequency of use of the traffic medicine website.

\section{Comparison with the existing literature}

The finding that the preconsultation patient questionnaire and the reference guide were considered useful could be explained in two ways. First, physicians may feel that they are not sufficiently trained and/or do not have the required competences to carry out the fitness-to-drive assessments. These two practical tools could help to reassure them, and, as such, they could be used as a model to guide these assessments. This assertion would be in line with previous research; for example, a survey carried out in Canada ( $\mathrm{n}=460$ GPs) showed that nearly half of GPs did not feel comfortable in assessing older drivers and the majority of GPs $(89 \%)$ were interested in receiving more training in this area. ${ }^{12}$ Another study carried out in Sweden and Finland ( $n=1682$ GPs) showed that only 21\% of Finnish and $18 \%$ of Swedish GPs felt that their training in traffic medicine was sufficient for assessing the driving fitness of older drivers. ${ }^{16}$ Second, the preconsultation patient questionnaire could offer time-saving benefits for physicians, in that it could be completed at home or in the waiting room, and, as such, the collection by physicians of relevant medical information during the medical visit could be carried out more quickly.

We also found that younger physicians were generally more likely to consider both of these practical tools useful, although the association with age was not statistically significant in multivariable analysis. This finding could be explained by the fact that younger physicians are less experienced physicians and are generally more in need of tools to improve their skills in this area. For example, several authors have shown that younger physicians tend to have higher adherence to guidelines than their older, more experienced counterparts. ${ }^{17-19}$ In England, a study showed that a 10-year increase in age was associated with halving odds of using elective surgical referral guidelines. ${ }^{19}$

Interestingly, the proportion of physicians in our study who found the instruments useful was not dependent on their medical specialty (medical assessors or regular practice GPs), nor did the results vary with the number of assessments performed per week or with the level of adherence to Swiss guidelines (estimated by the number of recommended procedures performed by physicians during the fitness-to-drive assessments: $\geq 15$ vs $<15$ procedures). Note that an in-depth discussion on this topic (level of adherence to Swiss guidelines) can be found in the practice review. ${ }^{11}$

Surprisingly, although the majority of physicians found these instruments useful, less than one-fifth of physicians regularly used the information sources provided by the Swiss traffic medicine website. They were however gender effects with female physicians using the traffic medicine website resource a little more than their male counterparts: $25 \%$ vs $13 \%$ for male physicians. In addition, almost one-third of physicians have never used them, perhaps because they were unfamiliar with them. This would be in line with two American studies showing that physicians were not aware of existing fitness-to-drive assessment guidelines. ${ }^{12} 13$ These findings suggest that physicians assessing the fitness to drive of older patients should be more aware of available sources of information, particularly male physicians. Regular training of physicians, which is currently not the case in our country, would be an ideal opportunity to assess their knowledge and provide them with the necessary information on available medical resources. It should be noted, however, that the information available to physicians to help them assess older drivers, in particular the Swiss recommendations, is not evidence-based but only expert opinions.

\section{Perspectives}

The implementation of a preconsultation patient questionnaire, ideally in both paper and online formats, would be in line with the general trend towards the development and promotion of self-assessment instruments that favour self-regulation and support the transition to driving cessation. ${ }^{20}{ }^{21}$ Thus, the preconsultation patient questionnaire could be regularly completed by older drivers at home and provide an opportunity for feedback and increased awareness of their fitness to drive, for example, by asking them to self-report health concerns. ${ }^{20}{ }^{21}$ However, patients' perceptions of driving ability and actual driving ability may differ significantly, 
and many older drivers with medical conditions do not appropriately self-regulate their driving (especially those with dementia). ${ }^{22}$ For this reason, evidence-based assessments of fitness to drive can assist physicians in determining the driving ability of patients who are medically impaired.

\section{Limitations}

First, only physicians practising in Western Switzerland were included in the study; these physicians are not necessarily representative of all physicians practising in Switzerland. Second, the study data were based on the answers to a self-administered questionnaire and therefore are subject to self-report bias. Third, we did not record any data on physicians who declined to participate in the study. Finally, this study assessed the perceived usefulness of practical tools (preconsultation patient questionnaire and reference guide) and the use of the traffic medicine website. It would also have been useful to examine whether these resources actually have an effect on how physicians assess older drivers, their knowledge and their confidence in fitness-to-drive assessments.

\section{CONCLUSIONS}

Many physicians in this study found the preconsultation patient questionnaire and reference guide useful to guide them for assessing the driving ability of older drivers, but only a minority regularly used the information sources provided by the traffic medicine website. Future studies should explore the reasons why many physicians do not use available sources of information. In addition, further research is needed to find out what older drivers and drivers' associations think about the use of these practical tools.

Correction notice This article has been corrected since it was published Online First. A typo has been fixed in the abstract.

Acknowledgements PS would like to warmly thank all the doctors who participated in the study, Amir Moussa, our research assistant, and Dagmar Haller, Philippe Huber, Yolanda Mueller and Leonardo Silvestri for their support and assistance throughout the study.

Contributors PS was involved in the conception, data analysis and data interpretation. PS drafted the first version of the manuscript. PS can be contacted for access to the data set underlying the current analysis.

Funding This project was supported by institutional funding from the Faculty of Medicine, University of Geneva.

Disclaimer The funders had no role in study design, data collection and analysis, decision to publish, or preparation of the manuscript.

Competing interests None declared.

Patient consent for publication Not required.

Provenance and peer review Not commissioned; externally peer reviewed. Data availability statement Data are available upon request.

Open access This is an open access article distributed in accordance with the Creative Commons Attribution Non Commercial (CC BY-NC 4.0) license, which permits others to distribute, remix, adapt, build upon this work non-commercially, and license their derivative works on different terms, provided the original work is properly cited, appropriate credit is given, any changes made indicated, and the use is non-commercial. See: http://creativecommons.org/licenses/by-nc/4.0/.

ORCID iD

Paul Sebo http://orcid.org/0000-0001-7616-0017

\section{REFERENCES}

1 Meuser TM, Carr DB, Ulfarsson GF. Motor-vehicle crash history and licensing outcomes for older drivers reported as medically impaired in Missouri. Accid Anal Prev 2009;41:246-52.

2 Dobbs BM. Aging baby boomers-a blessing or challenge for driver licensing authorities. Traffic Inj Prev 2008;9:379-86.

3 Rapport SINUS 2017 - Niveau de sécurité et accidents dans la circulation routière en 2016.pdf [Internet]. [cited 2018 Apr 22]. Available: https://www.bfu.ch/media/ihbnl5mb/sinus_2017_fr.pdf

4 Rizzo M. Impaired driving from medical conditions: a 70-yearold man trying to decide if he should continue driving. JAMA 2011;305:1018-26.

5 Redelmeier DA, Yarnell CJ, Thiruchelvam D, et al. Physicians' warnings for unfit drivers and the risk of trauma from road crashes. $N$ Engl J Med 2012;367:1228-36.

6 Driver Licensing Legislation.pdf [Internet]. [cited 2018 Nov 18]. Available: https://pdfs.semanticscholar.org/5cba/23811288f1c7 9d886373c6d6cd10d414c4f5.pdf?_ga=2.38081699.1816448984. 1586668786-1999220722.1577607799

7 Siren A, Meng A. Cognitive screening of older drivers does not produce safety benefits. Accid Anal Prev 2012;45:634-8.

8 Mitchell CGBK. The licensing of older drivers in Europe-a case study. Traffic Inj Prev 2008;9:360-6.

9 Hakamies-Blomqvist L, Johansson K, Lundberg C. Medical screening of older drivers as a traffic safety measure-a comparative Finnish-Swedish evaluation study. J Am Geriatr Soc 1996;44:650-3.

10 Sebo P, Vaucher P, Haller D, et al. What is the profile of older drivers considered medically unfit to drive? A cross-sectional survey in Western Switzerland. Swiss Med Wkly 2018;148:w14684.

11 Sebo P, Haller DM, Favrat B, et al. Adherence to guidelines when evaluating fitness-to-drive in the elderly: a practice review of Swiss physicians. Swiss Med Wkly 2018;148:w14632.

12 Jang RW, Man-Son-Hing M, Molnar FJ, et al. Family physicians' attitudes and practices regarding assessments of medical fitness to drive in older persons. J Gen Intern Med 2007;22:531-43.

13 Miller DJ, Morley JE. Attitudes of physicians toward elderly drivers and driving policy. J Am Geriatr Soc 1993;41:722-4.

14 Lurie N, Slater J, McGovern P, et al. Preventive care for women. does the sex of the physician matter? N Engl J Med 1993;329:478-82.

15 Statistique_mdicale_2016_de_la_FMH1.pdf [Internet]. [cited 2017 Jun 24]. Available: https://contens30.fmh.ch/fmh/_files/pdf18/ Statistique_mdicale_2016_de_la_FMH1.pdf

16 Hakamies-Blomqvist L, Henriksson P, Falkmer T, et al. Attitudes of primary care physicians toward older drivers: a Finnish-Swedish comparison. J Appl Gerontol 2002;21:58-69.

17 Tell D, Engström S, Mölstad S. Adherence to guidelines on antibiotic treatment for respiratory tract infections in various categories of physicians: a retrospective cross-sectional study of data from electronic patient records. BMJ Open 2015;5:e008096.

18 Harris MF, Lloyd J, Krastev Y, et al. Routine use of clinical management guidelines in Australian general practice. Aust J Prim Health 2014;20:41-6.

19 Blundell N, Taylor-Phillips S, Spitzer D, et al. Elective surgical referral guidelines - background educational material or essential shared decision making tool? A survey of GPs' in England. BMC Fam Pract 2011;12:92.

20 dl_study_on_training_testing_med_fitness.pdf [Internet]. [cited 2018 Nov 18]. Available: https://ec.europa.eu/transport/road_safety/sites/ roadsafety/files/dl study on training testing med fitness.pdf

21 Driving Choices for the Older Motorist.pdf [Internet]. [cited 2018 Nov 18]. Available: https://www.racfoundation.org/assets/rac_foundation/ content/downloadables/driving_choices_for_the_older_motorist_ lang_parkes_and_fernandez_medina_0213.pdf

22 American Geriatrics Society \& Pomidor A. Clinician's guide to assessing and counseling older drivers. (Report No. DOT HS 812 228). 3rd edn. Washington, DC: National Highway Traffic Safety Administration, 2013. 